\title{
Um material do tempo: as crônicas machadianas
}

\author{
Salete de Almeida Cara \\ (Universidade de São Paulo)
}

\begin{abstract}
RESUMO: PARA DAR CONTA DO TRATAMENTO QUE MACHADO DE ASSIS CONFERE AOS ASSUNTOS BRASILEIROS NAS SUAS CRÔNICAS É IMPORTANTE AFASTAR-SE DA NOÇÃO DE GÊNERO NORMATIVO, O QUE NÃO SE CONFIGURA COMO OPÇÃO TEÓRICA PRÉVIA AO OBJETO CRÔNICA, MAS, AO CONTRÁRIO, COMO PROPOSTA EXIGIDA PELO PRÓPRIO TRABALHO DO CRONISTA. NOS TERMOS DE UM PROJETO DE ANÁLISE LITERÁRIA E COMPARATIVA, TRATA-SE DE PENSAR O OBJETO ANALISADO ENQUANTO MATERIAL HISTÓRICO-SOCIAL.
\end{abstract}

ABSTRACT: IN ORDER TO UNDERSTAND THE WAY MACHADO DE ASSIS TREATS SOME BRAZILIAN ISSUES IN HIS CHRONICLES, IT IS IMPORTANT TO MOVE AWAY FROM THE NOTION OF NORMATIVE GENRE, WHICH IS NOT A THEORETIC OPTION PREVIOUS TO THE CHRONICLE AS AN OBJECT, BUT, ON THE CONTRARY, IS A REQUIREMENT OF THE CHRONICLER'S OWN WORK. WITHIN THE LIMITS OF A COMPARATIVE AND LITERARY ANALYSIS PROJECT, THIS IS RELATED TO CONSIDERING THE ANALYZED OBJECT AS A HISTORICAL-SOCIAL MATERIAL.

PALAVRAS-CHAVE: CRÔNICA - EXPERIÊNCIA BRASILEIRA - MATERIAL HISTÓRICO. KEY-WORDS: CHRONICLE - BRAZILIAN EXPERIENCE - HISTORICAL MATERIAL. 
o âmbito de uma polêmica com Georg Lukács sobre o realismo, Bertolt Brecht afirmou que, para determinar o grau de realismo de uma obra, "em cada caso, é preciso comparar a representação da vida num trabalho de arte com a própria vida que está sendo representada, ao invés de compará-lo com outro trabalho". Mesmo retirada do contexto da polêmica, a afirmação leva a pensar no desafio que é encontrar modos de figurar o concreto - e, assim, questões historicamente postas - justamente para tornar possível sua abstração. "Novos problemas aparecem e pedem novos métodos". E ele continua: "a realidade muda; a fim de representá-la, os modos de representação devem mudar também" (cf. BRECHT, 1977: 82 e 85).

Quando Machado de Assis cava uma nova forma de romance para tratar a matéria brasileira (como chama Roberto Schwarz), sua escolha formal exige que o leitor vá além do objeto - o romance - que, afinal, apreende, expõe e figura ficcionalmente problemas de uma sociabilidade particular. Mesmo assim, o escritor por certo já sabia que, aos seus próprios contemporâneos, a tarefa seria dificilima.

Exigência que não é fácil de ser atendida ainda hoje, pois implica uma posição de leitura que pede, no mínimo, interesse pelas contradições do tempo em que o romance foi escrito (e que vem de par com interesse pelos desafios do presente do leitor) e empenho em ultrapassar o plano das descrições de formas literárias. Nesse sentido, mesmo o leitor atento de Machado vem sendo desafiado desde as crônicas escritas nos anos 60 e 70.

Já naquelas crônicas, procedimentos narrativos como ironia e alusão remetiam ao torneio arcaico do romance setecentista para dar conta da tensão que atravessava o que parecia ser (mas não era) uma simples ratificação da opinião pública do tempo e que era, ao mesmo tempo, uma apreensão distanciada e crítica do funcionamento do país escravocrata e sua inserção no mundo. Nem por isso, todavia, as crônicas chegaram a causar antipatias fundas nos leitores do tempo. O feito é notável. Vale observar que uma consciência da distância que separava o autor do leitor seu contemporâneo será claramente exposta pela forma do romance a partir de $1880 .{ }^{1}$

Segundo o autor ficcional de Memórias póstumas de Brás Cubas, em "Ao leitor", haveria "gente grave" o suficiente para achar naquele livro "umas apa-

1 Helio de Seixas Guimarães mostra que, nos anos 70, Machado de Assis já não tem a mesma disponibilidade missionária que demonstrava nos primeiros artigos de jornal (cf. GUIMARÃES, 2004). 
rências de puro romance", e "gente frívola" o suficiente para se decepcionar com um romance pouco usual. "Trata-se de uma obra difusa, na qual eu, Brás Cubas, se adotei a forma livre de um Sterne ou de um Xavier de Maistre, não sei se lhe meti algumas rabugens de pessimismo", explica Cubas, que, todavia, não desanima do seu propósito de "angariar simpatias da opinião".

$\mathrm{Na}$ verdade, graves ou frívolos, os leitores do tempo por certo terão se debatido entre suas próprias expectativas sem chegar a apreender todo o alcance daquilo que o escritor vinha produzindo, nem a constituir um público à altura dos seus romances. É curioso verificar ou imaginar de que modo, graves ou frívolos, eles podem ter lido essas crônicas, contos e romances que, cada vez mais impertinentes, lhe esfregavam na cara a situação da mulher e do agregado, o autoritarismo patriarcal, a escravidão no país e, conseqüentemente, deveriam mexer com os brios e as meias-ilusões cultivadas pela nossa elite quanto à inserção do Brasil no mundo civilizado.

Como nos conta Machado de Assis no prólogo da terceira edição do seu romance de 1891, Brás Cubas estava ali respondendo a leitores como Capistrano de Abreu (será mesmo um romance?, perguntara o crítico) e Macedo Soares que, em "carta amigável" ao autor, apontara semelhanças com Garrett. Retomando aquela nota de Cubas ao leitor, o escritor sugere o pulo do gato: "se toda essa gente viajou", a viagem de Cubas terá sido "à roda da vida"; se há traço particular na sua personagem, há de ser as "rabugens de pessimismo", mas, finalmente, o romance em questão (uma “taça”) levaria um “outro vinho”, diferente do já contido nos modelos detectados pelos leitores e confessados pelo narrador-autor - Xavier de Maistre, Garrett, Sterne. De que novo vinho se trata? (cf. ASSIS, 1985: 512-523).

Machado de Assis não se furta a revelar a vida nacional pelo seu lado mais arrevesado, justamente onde a empáfia nacional pensava ver o melhor dos mundos e o passaporte para um futuro radioso, a saber, na formação das elites do país, cujo centralismo imperial ele acabava por preferir diante do federalismo imposto pelas oligarquias regionais. Uma opção por certo sem maiores entusiasmos, como não podia deixar de ser para um escritor atento às condições do seu país.

Não por acaso, o fim da década de 60 será retomada na produção ficcional dos anos 80 como um momento decisivo para a constituição pouco auspiciosa dos nossos rumos políticos e econômicos, e para a definição das relações sociais e da nossa vida ideológica que, também não por acaso, se constituía levan- 
do em consideração o "homem livre" e as relações de favor, e não nossa relação produtiva fundamental baseada no escravismo (cf. SCHWARZ, 2000: 15-16).

Ao comentar os rumos do desgaste do Império de olho nos seus desdobramentos republicanos, Sergio Buarque de Holanda lembra que em plena crise econômica mundial, nos anos 1870, a obtenção de empréstimos ingleses a altos juros era vista como sinal de prestígio, e que o papel da Guerra do Paraguai, da tentativa de conferir hegemonia militar ao país e da lei do Ventre Livre foram, antes, o de abrir oportunidades de negócios dando em especulação desenfreada (cf. HOLANDA, 1985: 7).

O que pode intrigar o leitor de hoje que lê o conjunto da obra do escritor é como ela foi capaz de figurar a matéria brasileira, incluindo os leitores como parte dela, de modo mais desassombrado e libertário nas crônicas da década de 1870 do que nos romances desses mesmos anos. Para tentar responder a isso, creio ser necessário descartar a hipótese de pensar as crônicas como gênero literário, no sentido tradicional de modelos de estilo ou discurso. Por não se encaixarem num âmbito normativo, as crônicas acabaram trazendo ao escritor a possibilidade de enfrentar uma dialética particular entre forma e conteúdo.

É importante insistir, portanto, que a forma das crônicas não se apresentava ao escritor como já estabelecida, tal qual a forma hegemônica do romance com origem na experiência européia e em trânsito internacional. Nesse último caso, o traslado da forma impunha obediência, adaptações ou transformações radicais. Por isso, no caso do romance, fez-se necessário a revolução formal que Machado de Assis fará em 1880, a partir de tensões e contradições internas entre enunciado da forma e enunciado do conteúdo, na passagem do modelo europeu para a experiência brasileira.

É Peter Szondi que, em Teoria do drama moderno, retoma a idéia hegeliana da forma como conteúdo "precipitado" e especifica a dialética entre conteúdo e forma, em termos de enunciado da forma (afinal, uma forma também tem a dizer) e enunciado do conteúdo. Sempre concernidos um ao outro num determinado tempo histórico, eles seriam contraditórios quando "o enunciado formal, estabelecido e não questionado é posto em questão pelo conteúdo”. Desse modo Szondi explica a crise da forma do drama, no qual o diálogo conferia centralidade a relações de intersubjetividade já insustentáveis na experiência moderna (cf. SZONDI, 2001). 
Volto ao caso das crônicas, vindas de Paris no século XIX como textos jornalísticos, os folhetins, para indagar se, pela sua própria constituição interna e externa, elas não seriam um material histórico do tempo que, aqui chegando, deram mostras de conter potencialidades capazes de dar conta das contradições da vida brasileira e dos próprios leitores de jornal. Se assim for, as crônicas ofereceram um campo de conteúdos e formas que Machado de Assis foi capaz de explorar com olho crítico. De modo que fazer crônicas foi, para Machado de Assis, um modo de mergulhar nas mediações já inscritas e dispostas naquele material, assim como na matéria brasileira. ${ }^{2}$

O trato mais livre e também mais comprometido da matéria incluía, nessa linha, a constituição de um narrador-cronista que chegava a assumir caráter ficcional para tornar mais eficaz (e também mais ambíguo) o alcance do olho crítico do escritor. Desse modo o narrador das crônicas se expõe como personagem em construção, procedimento plenamente alcançado nas crônicas dos anos 80. Já nas primeiras crônicas, no entanto, é ingênuo identificar de modo simples o narrador ao próprio autor, que pode atuar na elaboração do material como um diretor de cena que olha e comenta, de fora e à distância, os cenários e as personagens tendo o próprio cronista como uma personagem dentre outras.

"Novos problemas aparecem e pedem novos métodos", escreveu Brecht. Eis um caminho para pensar a singularidade dos desafios enfrentados por Machado enquanto cronista e enquanto romancista. Observar as primeiras formulações de Machado de Assis sobre a crônica, no início de sua atividade, pode iluminar as potencialidades, acima referidas, que as crônicas dispunham para o trabalho do escritor naquele momento. Por isso mesmo elas acabaram constituindo um campo de força na sua produção literária ao longo dos anos.

A primeira referência à crônica aparece na série "Aquarelas", publicada em $O$ espelho, em 1859. Ali ele diz que a crônica brasileira é uma mera pose francesa que, nos melhores casos, seria também uma "luz séria e vigorosa", uma "reflexão calma", uma "observação profunda" do cronista, todavia construídas com "devaneio e leviandade". Um horizonte de reflexão, profundidade, calma e seriedade, irremediavelmente contaminado pela forma leviana da crônica, transplantada como pose. Mas até que ponto é possível dizer que Machado valoriza o propósito de dar tal horizonte à crônica brasileira? Nesse

2 O conceito de material foi desenvolvido por Theodor Adorno em Teoria estética. 
mesmo texto outra leitura se insinua.

Na seqüência, a crônica aparece na definição famosa: uma "fusão admirável do útil e do fútil, o parto curioso e singular do sério, consorciado com o frivolo". Se essa definição não for reduzida à aparência de mera fórmula conciliadora e positiva$\mathrm{da}$, que ratificaria a valorização da combinação (estranha, vamos convir desde já) entre "pose francesa", frivolidade, devaneio, reflexão, seriedade e vigor, ela não deixará passar batido as possibilidades abertas pela combinação. "Fusão entre útil e fútil" como "parto curioso e singular" do sério e do frívolo: um precipitado que, misturado nos enunciados da forma e do conteúdo, irá encorpando o vinho que será vertido na taça machadiana depois de 1880 .

Essa “fusão admirável do útil e do fútil" é um sintoma perverso, presente também nas formas da vida social brasileira observada pelo escritor, e é com ela que ele vai respondendo, na prática cotidiana como cronista, a máxima com que tinha encerrado a série "Aquarelas": "escrever em folhetim e ser brasileiro é difícil". Faz parte de sua resposta quase sempre cifrada por imposição do seu próprio trato crítico, a inclusão dos leitores a quem não caía mal a pose francesa do folhetinista brasileiro.

Armando "uma grossa tenda lírica no meio do deserto" ou em chão lamacento, eles acreditavam estar num boulevard ou num café parisiense, ao comentar os acontecimentos do Rio de Janeiro e da rua do Ouvidor: eis um tema sempre pressuposto e implícito.Nesse passo é que a própria forma da crônica carregou consigo seus leitores - aquela gente "de bem" das nossas classes dominantes e letradas, a quem era dado a Machado de Assis conviver.

Em 1859 ele já sabia que "todos os leitores estão de posse deste traço de parasita literário", a saber, gente que vende e compra gato por lebre exibindo-se no jornal, no livro e nos teatro onde recitava. Com "adeptos, simpatia, aplausos". Tendo o capricho como musa, a crônica poderia ser uma "conversa sem assunto" e passar, de modo ligeiro, de chapéus e moda para a prosa clássica alemã e o romance de um professor de Guaratiba. Em 1869, a figura que representa o cronista será um “anão de circo”. Em 1877, a crônica será vista como um bate-papo entre duas vizinhas que jogam conversa fora, sentadas à porta da casa depois do jantar.

O caráter fortuito da crônica apanha, assim, como tipo social, o próprio cronista e seus leitores - livres-atiradores que tratavam de tudo um pouco ao pé do ouvido uns dos outros. O "anão de circo" que teria a função de divertir a platéia, e que parece ser uma das personae do cronista, está na medida exata do leitor com que conta o autor. Nesse momento, uma das primeiras crônicas 
de Machado mostra que não cabe supor que ele estaria encampando a distinção levada a sério pelo cronista (uma personagem?) e, por certo, pelo leitor: a distinção entre os simples folhetinistas e os chamados "verdadeiros artistas", que executariam as tarefas mais nobres.

Donde o sentido mais fundo da exibida facilidade de passar à vontade de um assunto para outro, que tem a medida certa do freguês - a diminuta elite de $36 \%$ da população que sabia ler e escrever, como se lê numa crônica de 1876, onde o cronista se mostra deslumbrado com os cantores líricos da temporada e as exposições de quinta categoria, não é preciso muito para concluir: " na hora em que escrevo essas linhas, preparo-me para ir ver um sapatinho de cetim - o sapatinho que Dona Lucinda nos trouxe da Europa e que o Furtado Coelho vai mostrar ao público fluminense". ${ }^{3}$

Uma elite pródiga em observações conservadoras, em tom ligeiro, sobre questões graves como a emancipação dos escravos, já passados cinco anos da Lei do Ventre Livre: "um homem do meu conhecimento suspira pelo azorrague", comenta o cronista. De onde fala esse cronista? Numa crônica de agosto de 1876, de "História de quinze dias", a ironia do cronista-narrador alcança uma explicitação inequívoca, mas quem sabe mal compreendida:

Hoje posso espectorar meia dúzia de bernardices sem que o leitor dê por elas. A razão não é outra senão a de ser o leitor um homem que se respeita, ama o belo, possui costumes elegantes: conseguintemente, não tem orelhas para crônicas, nem outras cousas ínfimas.

De onde fala o cronista machadiano? A crônica de 16 de junho de 1878 de "Notas Semanais" dá a medida da tensão entre cronista e leitor: o cronista se expõe como um "pobre-diabo" sem tribuna ("de mais a mais míope, cabeçudo e prosaico"), e ao leitor como alguém que nasceu com a "bossa da ilegalidade" ao conceber a legalidade como "um pau de dois bicos", que serve melhor a si mesmo do que aos outros ("não me refiro aos sobrinhos do leitor, nem a seus compadres, nem a seus amigos; mas tão-somente ao próprio leitor”)

A defesa da legalidade pelo cronista carrega também um traço elitista próprio de quem acredita na reforma dos costumes pelo alto, atitude que compõe

3 Para as referências das crônicas, cf. Obra completa, v. III (Rio de Janeiro: Nova Aguilar, 1985). Cf. tb. Assis (1990). 
o que parece ter sido o projeto ideológico machadiano dos primeiros tempos ("o leitor não compreende que [...] esse subalterno que transgride as barreiras da lei, é simplesmente um produto do próprio leitor”). No entanto, algo mais se avizinha nessa crença reformista, trazido pela ironia cortante do retrato do leitor, que coloca a própria crença sob suspeita de ser uma mera ilusão.

Afinal, o retrato apanha uma grave contradição histórica - nada fácil de ser superada -, constitutiva do nosso processo de sociabilidade:

o leitor (perdoe a sua ausência) é um estimável cavalheiro, patriota, resoluto, manso, mas persuadido de que as coisas públicas andam mal, ao passo que as coisas particulares andam bem; sem advertir que, a ser exata a primeira parte, a segunda forçosamente não o é; e a sê-lo a segunda, não o é a primeira. Um pouco mais de atenção daria ao leitor um pouco mais de eqüidade.

A coisa pública que vai mal e a vida privada que vai bem, sem que essa contradição seja vista como um problema, conforma um motivo largamente presente na ficção pós-1880. Muitos anos mais tarde, quando escrever Memorial de Aires, publicado em 1908, o narrador implícito terá plena consciência de que o que parecia anormal - a dissonância entre a vida pública e a vida privada - é sintoma de uma dissociação muito própria da impossibilidade de construção de um espaço verdadeiramente público no país, que tivesse como contrapartida uma relação efetiva dos seus interesses com os interesses privados.

No dia 14 de maio de 1888, voltando da casa dos Aguiar, Aires observa que "não há alegria pública que valha uma boa alegria particular", entendendo as razões particulares dos amigos. Também para ele a alegria pela Abolição passara como um prazer fortuito, embora providencial, porque ligado a interesses particulares que estavam em outro lugar que não o caráter público da causa da liberdade dos escravos, tudo convergindo para amplos e abstratos movimentos atemporais. "Ainda bem que acabamos com isso. Era tempo, Embora queimemos todas as leis, decretos e avisos, não podermos acabar com os atos particulares, escrituras e inventários, nem apagar a instituição da história, ou até da poesia". 4

4 Cf. Memorial de Aires, in Obra crítica, vol. I, ob. cit., p. Para uma análise deste romance cf. Gledson (1986: 215-255). 
Nos anos 80, o cronista assumirá algumas vezes o papel de um tipo amalucado garantindo o teor de verdade dos seus próprios negaceios: "Eu pertenço a uma familia de profetas après coup, post facto, depois do gato morto, ou como melhor nome tenha em holandês. Por isso digo, e juro se necessário for, que toda a história dessa lei de 13 de maio estava por mim prevista [...]". O tema do oportunismo político costura as crônicas da Gazeta de Notícias nos anos 80, uma data chave: "Balas de estalo" e as sete crônicas em diálogo de "A+B".

Como se vê, desde o início o cronista foi tomando gosto no retrato dos estimados cavalheiros que compunham a sociedade brasileira, junto com os escravos libertos e os homens livres. A leitura das crônicas nos mostra ainda que a inserção do país no mundo moderno e o nível esgarçado da nossa organização social dependem um do outro. Assim, em 1894, esse leitor muito brasileiro de Montaigne, que foi Machado de Assis, estabelece um preciso e irônico juízo histórico de um tópico de larga tradição humanista e liberal, a liberdade. A penada aparentemente casual lhe serve para comparar os usos de tópicos da cena ideológica européia na cena contemporânea brasileira.

E escreve: "A liberdade é um mistério, escreveu Montaigne, e eu acrescento que o monopólio é outro mistério, e, se tudo são mistérios neste mundo, como no outro, fiquem-se com seus mistérios que eu vou aos meus espinafres". Ora, logo após a Abolição e com a modernização dos bondes elétricos, como lemos em outras crônicas, os burros também tiveram a "liberdade de morrer" de fraqueza e de fome, os escravos tiveram a liberdade de continuar recebendo petelecos, pontapés e salário irrisório (em mais uma referência à relação entre escravos e burros, um achado interpretativo de John Gledson), e homens livres como a engomadeira da Rua do Senhor dos Passos, tiveram a liberdade de "se oferecer em aluguel" ou, como aquele outro empregado doméstico, a liberdade de pronunciar ou não corretamente a palavra "debêntures", mas sempre perdendo todas as suas parcas economias e, como consolo, a liberdade de traduzir transações financeiras por "desventuras e patifarias", sem ser capaz de mudar uma linha do jogo em que se metia.

Como já lembrei em outra ocasião, a retomada machadiana do procedimento alusivo "dos ironistas do século XVIII" apontada por Antonio Candido, marcadamente a partir dos anos 80, talvez possa ter começado a se instalar ainda nos fins dos anos 60 e começo dos anos 70, por imposição do "anormal 
corriqueiro" que sustentava as relações privadas agressivamente cordiais e a inexistência de um espaço público na nossa sociedade escravocrata. ${ }^{5}$

Segundo o crítico, o escritor teria conferido à bisbilhotice a função de lembrar "ao leitor que atrás dele [do narrador bisbilhoteiro] estava a voz convencional", num contraponto mesclado e numa implicação mútua entre um e outro, dando no que poderíamos chamar convenção bisbilhoteira como marca de um enredo social, onde as cordiais relações de favor estavam impregnadas pela crueldade efetiva do mando. As crônicas como material do tempo davam chance ao escritor de expor e ajuizar sobre essa experiência social em franca e sólida constituição, que exigiria do romancista a constituição de uma forma particular de romance realista.

\section{Referências Bibliográficas}

ASSIS, Machado de. Memórias póstumas de Brás Cubas. In: Obra completa, v. I. Rio de Janeiro: Nova Aguilar, 1985.

. Bons dias. Introdução e notas de John Gledson. São Paulo: Hucitec; Ed. Unicamp, 1990.

BRECHT, Bertolt. Against Gerorge Lukács. In: Aesthetics and Politics: the key-texts of the classic debate within german Marxism. London: Verso, 1977.

CANDIDO, Antonio. Esquema de Machado de Assis. In: Vários escritos. São Paulo: Duas Cidades, 1970.

GLEDSON, John. Fição e história. Rio de Janeiro: Paz e Terra, 1986.

GUIMARÃES, Helio de Seixas. Os leitores de Machado de Assis: o romance machadiano e o público de literatura do século XIX. São Paulo: Edusp; Nankin, 2004.

HOLANDA, Sergio Buarque de. Do império à República. In: O Brasil monárquico. São Paulo: Difel, 1985 (História Geral da Civilização Brasileira, t. II).

SCHWARZ, Roberto. As idéias fora do lugar. In: Ao vencedor as batatas. 5. ed. São Paulo: Duas Cidades; Ed. 34, 2000.

SZONDI, Peter. Teoria do drama moderno (1880-1950). São Paulo: Cosac \& Naify, 2001.

5 "A sua técnica consiste [...] em estabelecer um contraste entre a normalidade social dos fatos e a sua anormalidade essencial; ou em sugerir, sob a aparência do contrário, que o ato excepcional seria o ato normal, e anormal seria o ato corriqueiro. Aí está o motivo da sua modernidade, apesar do seu arcaísmo de superfície." (CANDIDO, 1970). 